\title{
LIM only 4 is overexpressed in late stage pancreas cancer Jun $\mathrm{Yu}^{1}$, Kenoki Ohuchida*1,2, Kohei Nakata ${ }^{3}$, Kazuhiro Mizumoto*1, Lin Cui ${ }^{1}$, Hayato Fujita ${ }^{1}$, Hiroshi Yamaguchi ${ }^{4}$, Takuya Egami ${ }^{1}$, Hidehisa Kitada ${ }^{1}$ and Masao Tanaka ${ }^{1}$
}

\begin{abstract}
Address: ${ }^{1}$ Department of Surgery and Oncology, Graduate School of Medical Sciences, Kyushu University, Fukuoka, Japan, ${ }^{2}$ Department of Integration of Advanced Medicine and Innovative Technology, Graduate School of Medical Sciences, Kyushu University, Fukuoka, Japan, ${ }^{3}$ Department of Anatomical Pathology, Graduate School of Medical Sciences, Kyushu University, Fukuoka, Japan and ${ }^{4}$ Department of Anatomical Pathology, Saitama Medical University International Medical Center, Saitama, Japan

Email: Jun Yu - shun@surg1.med.kyushu-u.ac.jp; Kenoki Ohuchida* - kenoki@surg1.med.kyushu-u.ac.jp; Kohei Nakata - knakata@surg1.med.kyushu-u.ac.jp; Kazuhiro Mizumoto* - mizumoto@surg1.med.kyushu-u.ac.jp; Lin Cui -y2kcl@surg1.med.kyushu-u.ac.jp; Hayato Fujita - hayato@surg1.med.kyushu-u.ac.jp; Hiroshi Yamaguchi - yamhiro@surg1.med.kyushu-u.ac.jp; Takuya Egami - takuya@surg1.med.kyushu-u.ac.jp; Hidehisa Kitada - hide@sug1.med.kyushu-u.ac.jp; Masao Tanaka - masaotan@surg1.med.kyushu-u.ac.jp

* Corresponding authors
\end{abstract}

Published: 22 December 2008

Molecular Cancer 2008, 7:93 doi:10.1 I86/1476-4598-7-93
Received: 4 August 2008

Accepted: 22 December 2008

This article is available from: http://www.molecular-cancer.com/content/7///93

(C) 2008 Yu et al; licensee BioMed Central Ltd.

This is an Open Access article distributed under the terms of the Creative Commons Attribution License (http://creativecommons.org/licenses/by/2.0), which permits unrestricted use, distribution, and reproduction in any medium, provided the original work is properly cited.

\begin{abstract}
Background: LIM-only 4 (LMO4), a member of the LIM-only (LMO) subfamily of LIM domaincontaining transcription factors, was initially reported to have an oncogenic role in breast cancer. We hypothesized that LMO4 may be related to pancreatic carcinogenesis as it is in breast carcinogenesis. If so, this could result in a better understanding of tumorigenesis in pancreatic cancer.
\end{abstract}

Methods: We measured LMO4 mRNA levels in cultured cells, pancreatic bulk tissues and microdissected target cells (normal ductal cells; pancreatic intraepithelial neoplasia-IB [PanIN-IB] cells; PanIN-2 cells; invasive ductal carcinoma [IDC] cells; intraductal papillary-mucinous adenoma [IPMA] cells; IPM borderline [IPMB] cells; and invasive and non-invasive IPM carcinoma [IPMC]) by quantitative real-time reverse transcription-polymerase chain reaction (qRT-PCR).

Results: 9 of 14 pancreatic cancer cell lines expressed higher levels of LMO4 mRNA than did the human pancreatic ductal epithelial cell line (HPDE). In bulk tissue samples, expression of LMO4 was higher in pancreatic carcinoma than in intraductal papillary-mucinous neoplasm (IPMN) or nonneoplastic pancreas $(p<0.000$ I for both). We carried out microdissection-based analyses. IDC cells expressed significantly higher levels of LMO4 than did normal ductal epithelia or PanIN-IB cells $(p<0.00$ I for both) or PanIN-2 cells $(p=0.014)$. IPMC cells expressed significantly higher levels of LMO4 than did normal ductal epithelia $(p<0.00 I)$, IPMA $(p<0.00 I)$ and IPMB cells $(p=0.003)$.

Conclusion: Pancreatic carcinomas (both IDC and IPMC) expressed significantly higher levels of LMO4 mRNA than did normal ductal epithelia, PanIN-IB, PanIN-2, IPMA and IPMB. These results suggested that $L M O 4$ is overexpressed at late stages in carcinogenesis of pancreatic cancer. 


\section{Introduction}

Pancreatic cancer is one of the most aggressive malignant tumors. It is the fifth leading cause of cancer death in Japan $[1,2]$ and has the lowest survival rate of any solid cancer [3]. Because the lack of specific symptoms in patients with pancreatic cancer makes early diagnosis difficult, initial diagnosis typically occurs when the tumor has reached an advanced stage [4]. A better understanding of pancreatic carcinogenesis is urgently needed to facilitate early detection. Pancreatic intraepithelial neoplasia (PanIN) and intraductal papillary-mucinous neoplasm (IPMN) were reported to be precursor lesions of pancreatic cancer [5-8]. Development of invasive ductal adenocarcinoma has been proposed to occur via two pathways [9-11], the PanIN-Invasive ductal carcinoma (IDC) progression pathway and the IPM adenoma (IPMA)-invasive IPM carcinoma (IPMC) pathway, although some specific subtypes of IPMN, such as intestinal-type IPMN, may not progress to invasive carcinoma through the same genetic pathway as PanIN. Longnecker et al [12] reported that PanIN-1 and IPMA showed mild dysplasia (grade 1), PanIN-2 and IPM borderline (IPMB) lesions showed moderate dysplasia (grade 2), and PanIN-3 and IPMC (carcinoma in situ [CIS]) showed severe dysplasia (grade 3).

LIM-only 4 (LMO4) is one of the four members (LMOs 1 , 2, 3 and 4) of the LIM-only subfamily of LIM domain proteins. LIM domains are an approximately 55-amino acid, cysteine-rich, zinc-binding motif that mediate proteinprotein interactions present in a variety of proteins including LIM homeobox proteins [13]. The nuclear LIM-only proteins (LMOs 1-4) lack a DNA-binding domain but still function as transcriptional regulators by recruiting other protein partners including transcription factors $[14,15]$. Kenny et al [13] reported the isolation and characterization of LMO4, a novel LIM-only gene that is highly expressed in the T-lymphocyte lineage, cranial neural crest cells, somites, dorsal limb bud mesenchyme, motor neurons and Schwann cell progenitors. As well as its role in development, there are several lines of evidence suggesting that LMO4 may have roles in oncogenesis [16]. LMO4, initially described as a human breast tumor autoantigen [17], was reported to have a role in maintaining proliferation of mammary epithelium and suggested that deregulation of this gene may contribute to breast tumorigenesis [18]. Additionally, Sum et al [19] found that LMO4 interacts with the cofactor CtIP and the tumor suppressor breast cancer 1 (BRCA1), and inhibits the transcriptional activity of BRCA1 in both yeast and mammalian cells by functional assays. They concluded that deregulation of LMO4 in breast epithelium directly contributes to breast neoplasia by altering the rate of cellular proliferation and promoting cell invasion. In 2005, Sum and colleagues reported that LMO4 mRNA was overex- pressed in 5 of 10 human breast cancer cell lines; in situ hybridization analysis of 177 primary invasive breast carcinomas revealed overexpression of LMO4 in 56\% of the specimens [20]. It has also been reported that expression of LMO4 is up-regulated at the invasive front of oral cancer, suggesting a role in cancer cell invasion [21]. It was recently reported that the bone morphogenic protein (BMP7) gene, which controls cell proliferation and apoptosis of mammary epithelial cells, is a direct target of LMO4 [22]. Both pancreatic cancer and breast cancer are known to have an epithelial origin while pancreatic cancer also reveals papillo-tubular structures that are similar to the histological characteristics of the initial breast cancer [23]. As well, known genetic changes in pancreatic cancer often involve the same genes as those found in breast cancer [24]. Taken together, these findings suggest that LMO4 has critical functions in pancreatic carcinogenesis as well as in normal development. Thus clarification of the role of LMO4 may be useful for diagnosis and/or treatment of pancreatic cancer. However, little is known about the role of $\mathrm{LMO} 4$ in pancreatic cancer and carcinogenesis.

To determine whether $\mathrm{LMO} 4$ is correlated with pancreatic cancer and carcinogenesis, we quantified LMO4 mRNA levels in cultured pancreatic cell lines, bulk tissues and microdissection-based target cells (including normal pancreatic ductal, PanIN-1B and PanIN-2, IDC, IPMA, IPMB and IPMC cells), by quantitative real-time reverse transcription-polymerase chain reaction (qRT-PCR). Our goal was to characterize LMO4 expression in the early and late stages of pancreatic carcinogenesis to clarify both if and when overexpression of LMO4 occurs.

\section{Materials and methods Cultured cells}

Fourteen pancreatic cancer cell lines, AsPC-1, KP-1N, KP2, KP-3, PANC-1, SUIT-2 (provided by Dr. H. Iguchi, National Shikoku Cancer Center, Matsuyama, Japan), MIA PaCa-2 (Japanese Cancer Resource Bank, Tokyo, Japan), NOR-P1 (established in our laboratory), CAPAN1, CAPAN-2, CFPAC-1, H48N, HS766T and SW1990 (American Type Culture Collection, Manassas, VA, USA), the HPDE cell line and six primary cultures of fibroblasts derived from pancreatic tumors were studied. Cells were maintained as described previously [25].

\section{Pancreatic tissues}

Tissue samples were obtained during surgery at Kyushu University Hospital (Fukuoka, Japan) as described previously [26]. In brief, tissue samples were removed and divided into at least three bulk tissue specimens. The first sample was immediately but temporarily preserved in cold PBS and then embedded in OCT compound (Sakura Findek, Tokyo, Japan), snap-frozen for microdissection within 1 hour after resection, and stored at $-80^{\circ} \mathrm{C}$ until 
use. The second sample was fixed in formalin, embedded in paraffin and cut into 4 - $\mu \mathrm{m}$-thick sections for hematoxylin and eosin (H\&E) staining. The third sample was immediately snap-frozen for bulk tissue analysis and stored at $-80^{\circ} \mathrm{C}$ until use. Tissues adjacent to the specimens were examined histologically and the diagnosis confirmed by two pathologists, Dr Hiroshi Yamaguchi and Dr Kohei Nakata (Figure 1). Written informed consent was obtained from all patients, and the study was approved by our institution's surveillance committee and conducted according to the Helsinki Declaration.

\section{RNA isolation}

Total RNA was extracted from cultured cells with a High Pure RNA Isolation Kit (Roche, Mannheim, Germany). Total RNA was extracted from bulk tissues with an RNeasy Mini Kit (Qiagen, Tokyo, Japan) following the manufacturer's protocol. Total RNA was extracted from cells isolated by microdissection with the standard acid guanidinium thiocyanate-phenol-chloroform protocol [27] with or without glycogen (Funakoshi, Tokyo, Japan) [26].

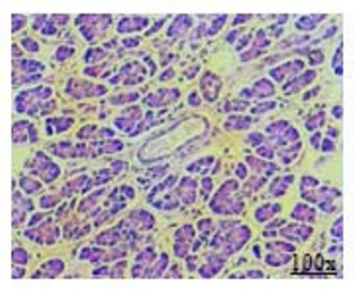

A

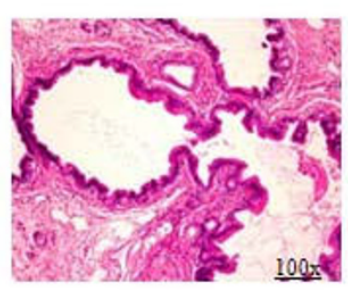

B

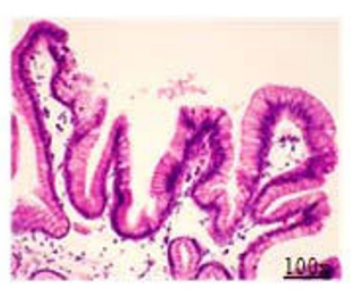

E

\section{Quantitative assessment of LMO4 level by real-time RT- PCR}

Quantitative real-time RT-PCR was performed with a QuantiTect SYBR Green RT-PCR Kit (Qiagen, Tokyo, Japan) with a Chromo ${ }^{\mathrm{TM}}$ System (Bio-Rad, Hercules, CA, USA). In brief, the reaction mixture was first incubated at $50^{\circ} \mathrm{C}$ for $30 \mathrm{~min}$ to allow for reverse transcription. PCR was initiated with one cycle of $95^{\circ} \mathrm{C}$ for $15 \mathrm{~min}$ to activate the modified Taq polymerase followed by 40 cycles of $94^{\circ} \mathrm{C}$ for $15 \mathrm{sec}, 55^{\circ} \mathrm{C}$ for $20 \mathrm{sec}$, and $72^{\circ} \mathrm{C}$ for $10 \mathrm{sec}$, and one cycle of $95^{\circ} \mathrm{C}$ for $0 \mathrm{sec}, 65^{\circ} \mathrm{C}$ for $15 \mathrm{sec}$ and $+0.1^{\circ} \mathrm{C} /$ sec to $95^{\circ} \mathrm{C}$ for melting analysis. Each sample was run in triplicate. The level of LMO4 mRNA expression was calculated from a standard curve constructed with total RNA from the SUIT-2 pancreatic cancer cell line. The range of threshold cycles was from 20-35 cycles for LMO4 primers (forward, 5'-GGA CCG CTT TCT GCT CTA TG-3'; reverse, 5'-AAG GAT CAT GCC ACT TTT GG-3'), and from 7-35 cycles for $18 \mathrm{~S}$ rRNA primers (forward 5'-GAT ATG CTC ATG TGG TGT TG-3'; reverse, 5'-AAT CTT CTT CAG TCG CTC CA-3'). Expressions of LMO4 mRNA were normalized to that of $18 S$ rRNA.

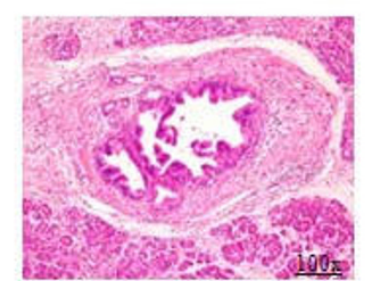

$\mathrm{C}$

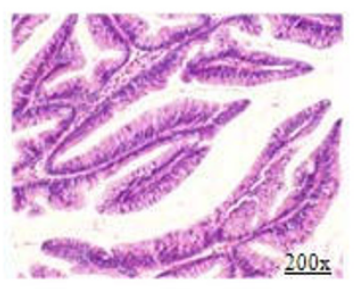

F

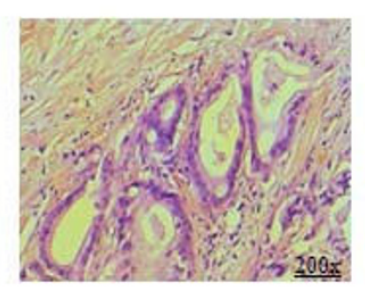

D

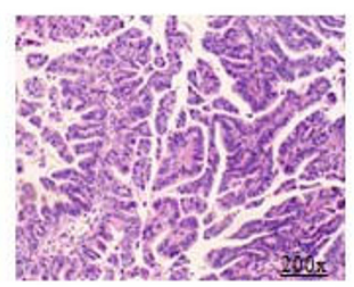

G

\section{Figure I}

Histologic examination of formalin-fixed, paraffin-embedded (FFPE) samples with hematoxylin and eosin (H\&E) staining. The stages of the PanIN-IDC pathway are shown as normal pancreatic ductal epithelia (A), pancreatic intraepithelial neoplasm-IB (PanIN-IB) (B), PanIN-2 (C) and invasive ductal carcinoma (IDC) (D). The stages of the intraductal papillary mucinous adenoma (IPMA)-intraductal papillary mucinous carcinoma (IPMC) pathway are shown as IPM adenoma (E), IPM borderline (F) and IPM carcinoma (G). (Magnifications of A to G are 100×, 100×, I00×, 200×, 100×, 200×, 200×, respectively). 


\section{Microdissection-based quantitative analysis of LMO4 mRNA}

Frozen tissues were cut into 8 - $\mu \mathrm{m}$-thick sections. IDC cells from 8 lesions, PanIN-2 cells from 3 lesions, PanIN-1B cells from 14 lesions, normal ductal epithelial cells from 13 ducts, IPMA cells from 13 lesions, IPMB cells from 15 lesions, and IPMC cells from 8 lesions, including 3 noninvasive IPMC lesions (CIS) and 5 invasive IPMC lesions, were selectively isolated with a laser microdissection and pressure catapulting system (P.A.L.M. Microlaser Technologies, Bernried, Germany) in accordance with the manufacturer's protocols (Figure 2) [28]. After microdissection,
Lane 1
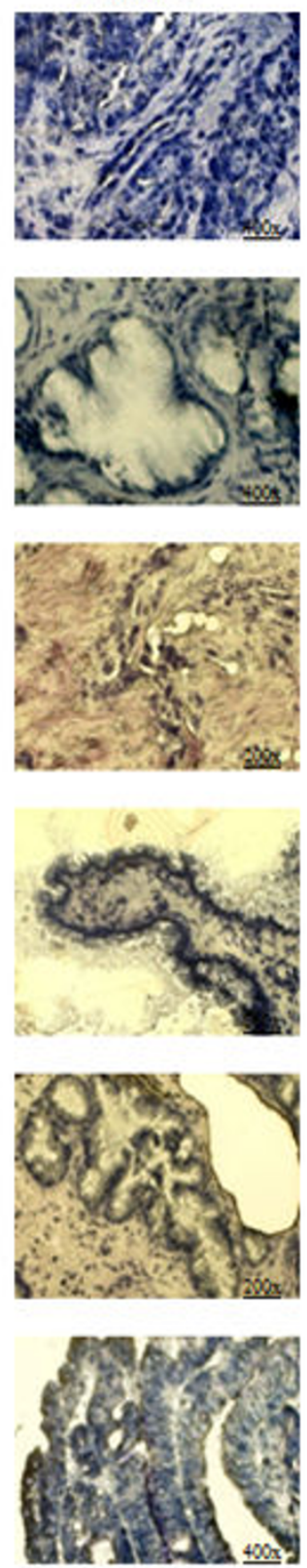

Lane 2
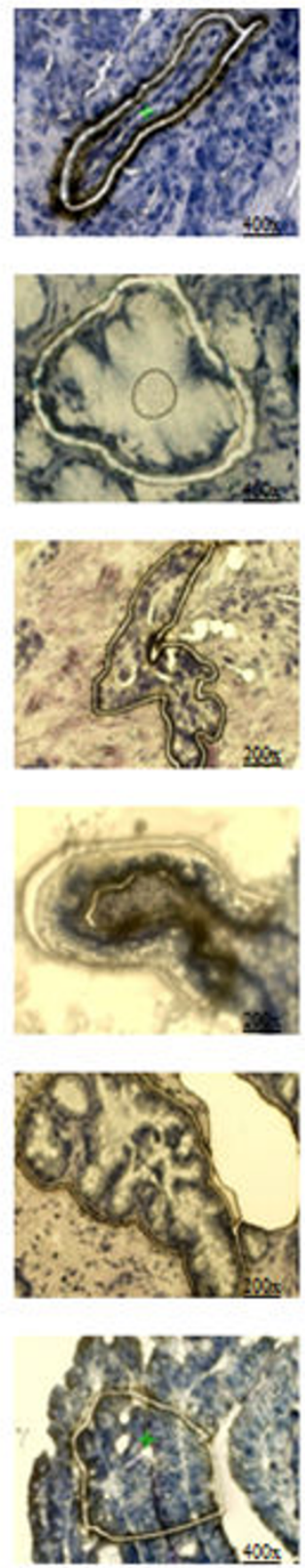

Lane 3
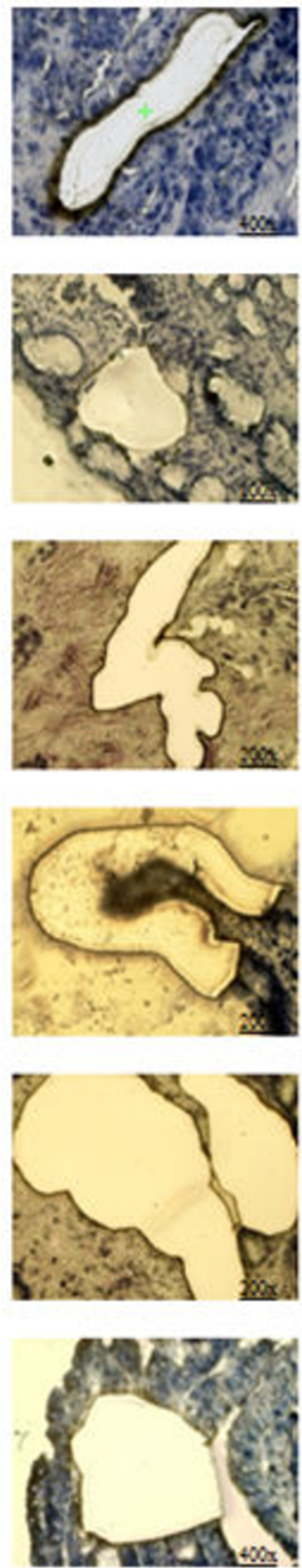

Lane 4

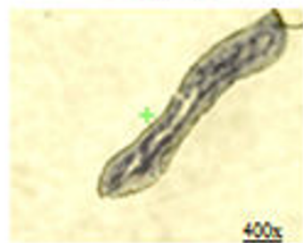

Normal ductal epithelia

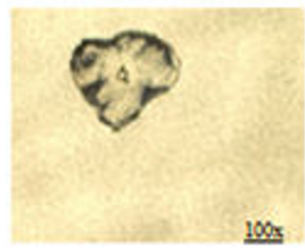

PanIN-1B

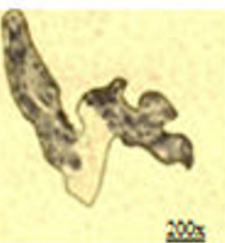

IDC

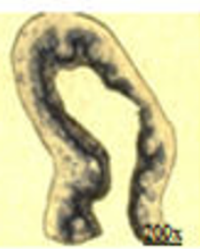

IPMA

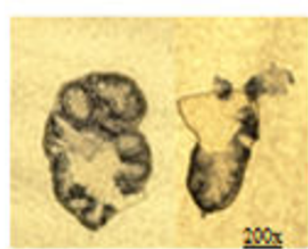

IPMB

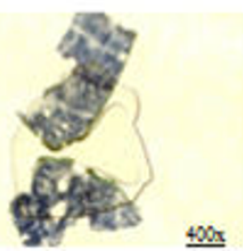

Figure 2

Pictures of pancreatic normal ductal epithelia, PanIN-IB, IDC, IPMA, IPMB and IPMC lesions stained with I\% toluidine blue. Lanes I to 4 show the process of microdissecting the target cells. Before cutting (lane I), after cutting (lane 2), rest of region (lane 3 ) and target cells in capture (lane 4). (The magnifications are shown on the pictures). 
total RNA was extracted from the selected cells and subjected to qRT-PCR for quantitative measurement of $\mathrm{LMO} 4$ as described previously [26].

\section{Statistical analysis}

Data were analyzed with multiple comparison in ANOVA (analysis of variance) and Bivariate Correlations with Statistics Package for Social Science (SPSS) software (SPSS Inc. Chicago, IL, USA) after Kolmogorov-Smirnov test to assure that each data set is showed a normal distribution. For multiple comparisons by ANOVA, we used the least significant difference (LSD) test and set the statistical significance at $p<0.05$. We used Spearman test for bivariate correlations.

\section{Results \\ Quantitative analysis of LMO4 expression in 14 pancreatic cancer cell lines, a non-neoplastic ductal epithelial cell line and six primary cultures of pancreatic fibroblasts}

We investigated $\mathrm{LMO} 4 \mathrm{mRNA}$ expression in 14 pancreatic cancer cell lines, HPDE, a normal pancreatic ductal cell line immortalized by transduction with the E6/E7 genes of human papillomavirus $16[29,30]$, and 6 primary cultures of pancreatic fibroblasts derived from resected pancreatic tumors. As shown in Figure 3, 9 of the 14 pancreatic cancer cell lines expressed higher levels of LMO4 than did HPDE. We also found that all 6 primary cultures of pancreatic fibroblasts expressed moderate levels of LMO4. Four pancreatic cancer cell lines, Hs766T, AsPC-1, KP-2 and KP-3, expressed higher levels of LMO4 than did any of the primary cultures of pancreatic fibroblasts. We next examined whether LMO4 expression is related to the origin of these cancer cell lines, but found no correlation between LMO4 expression and site of origin, such as primary or metastatic tumors (Figure 3).

\section{Quantitative analyses of LMO4 expression in bulk pancreatic tissues}

In the bulk tissue analyses, we measured LMO4 expression in pancreatic cancer tissues $(n=11)$, and non-neoplastic tissues $(n=20)$, normal pancreatic or chronic pancreatitis-related tissues, and non-malignant IPMN tissues $(n=11)$. As shown in Figure 4, LMO4 expression was highest in the pancreatic cancer tissues with a mean of 0.24 (95\% confidence interval [CI], $0.16-0.32$ ), whereas the LMO4 expression levels were 0.03 (95\% CI, $0.02-$ 0.04 ) in non-neoplastic tissues and 0.08 (95\% CI, 0.04 0.12 ) in non-malignant IPMN tissues. The mean LMO4 mRNA level in pancreatic cancer tissues was eight-fold higher than that in non-neoplastic tissues $(p<0.0001)$ and three-fold higher than that in non-malignant IPMN tissues $(p<0.0001)$. The mean LMO4 mRNA level in nonmalignant IPMN tissues was 2.7-fold higher than that in non-neoplastic tissues, although the difference was not statistically significant $(p=0.053)$. All data from bulk tis-

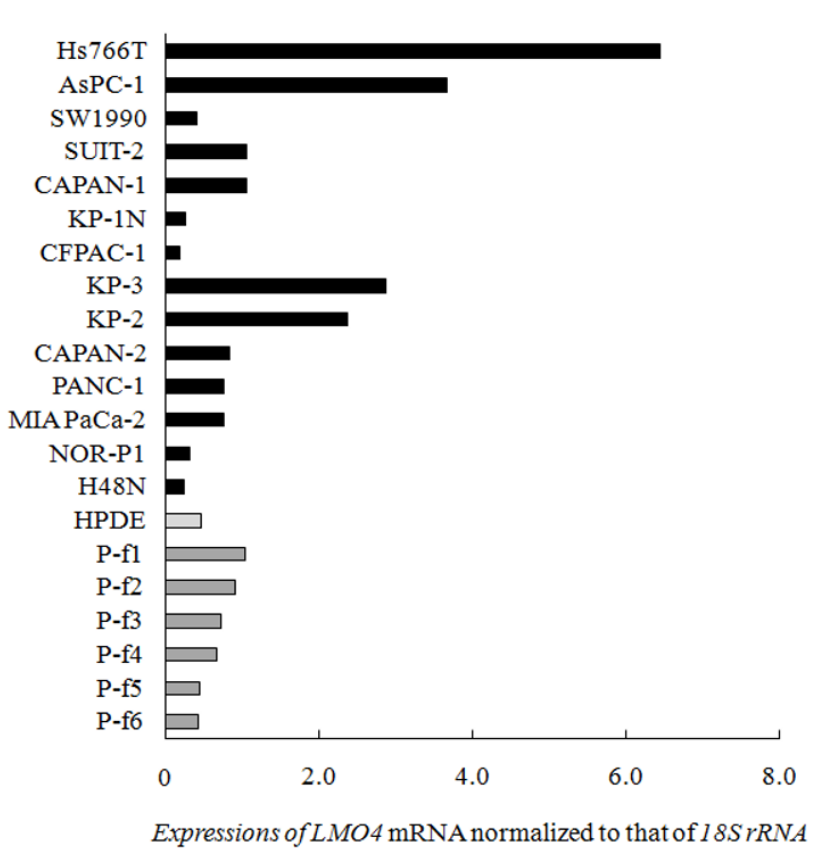

Figure 3

LMO4 expressions in pancreatic cancer cell lines, a human pancreatic ductal epithelial (HPDE) cell line and primary fibroblasts derived from pancreatic tumors. Hs766T, AsPC-I, SUIT-2, CAPAN-I, KP-3, KP-2, CAPAN-2, PANC-I and MIA PaCa-2 cells expressed significantly higher levels of LMO4 (median, I.07) than did the HPDE cells (median, 0.46). All 6 cultures of primary fibroblasts express moderate levels of LMO4 (median, 0.70 ). The difference in $L M O 4$ expression between the metastasis group (Hs766T, AsPC-I, SWI 990, NOR-PI, SUIT-2 and CAPAN-I; median $=1.06)$ and the non-metastasis group (KP-2, KP-3, CAPAN-2, PANC-I, MIA PaCa-2 and H48N; median =0.76) is not statistically significant $(p=0.75)$. Expression of $L M O 4$ mRNA was normalized to that of I8S rRNA.

sue analyses indicated that LMO4 was overexpressed in pancreatic cancer.

\section{Microdissection-based quantitative analysis of LMO4 expression in IDC, PanIN-2, PanIN-IB and normal ductal cells}

In general, bulk pancreatic tissues are composed of a various types of cells, including ductal epithelial, acinar, islet and mesenchymal cells, and fibroblasts. Cancer cells comprise only $30 \%-70 \%$ of the cells in bulk tissue specimens of pancreatic cancer [27]. Premalignant cells, such as PanINs, and normal ductal cells comprise even smaller percentages of the cells in non-malignant tissues. The results of our present analyses of cultured cells suggested that LMO4 was expressed in pancreatic fibroblasts (Figure 3 ). Therefore, to avoid the influence of contaminating non-ductal cells, we used a laser-microdissection (LMD) method to select specific ductal cells for further analysis. 


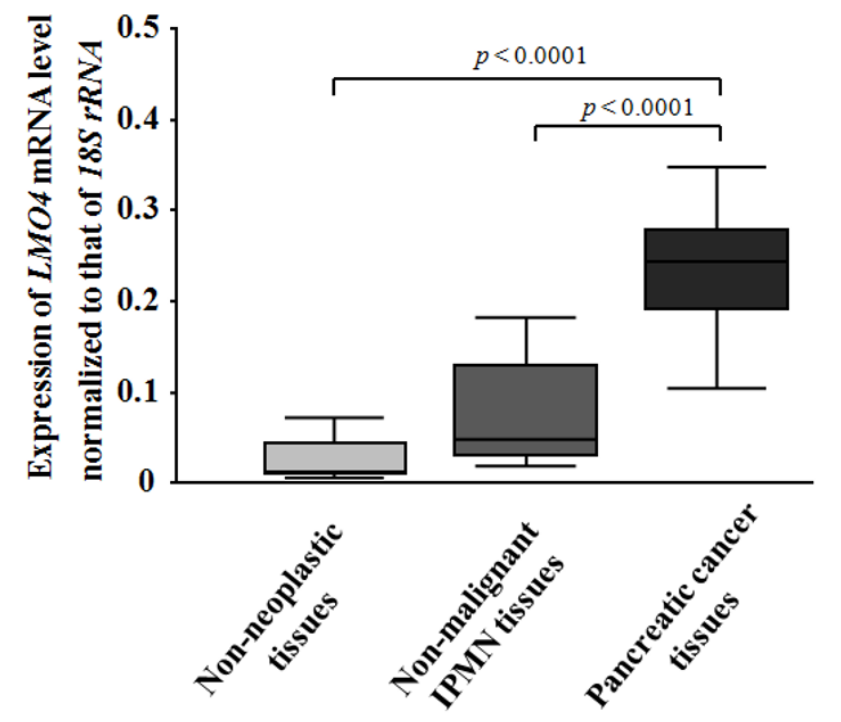

Figure 4

LMO4 expressions in bulk pancreatic tissues, including 20 non-neoplastic tissues, I I non-malignant IPMN tissues and I I pancreatic cancer tissues. The mean LMO4 expression value for pancreatic cancer samples is $0.24(95 \% \mathrm{Cl} ; 0.16-0.32)$, which is higher than the LMO4 level of non-malignant IPMN (mean, 0.08; $95 \% \mathrm{CI}, 0.04-$ 0.12 ) or non-neoplastic tissues (mean, $0.03 ; 95 \% \mathrm{Cl}, 0.02-$ 0.04). The difference in LMO4 expression between nonmalignant IPMN and non-neoplastic tissues is not statistically significant $(p=0.053)$. The bottom and the top edges of the box mark the lower bound and upper bound of the $95 \%$ Confidence Interval for the Mean, respectively. The center horizontal line is drawn at the sample mean. The center vertical lines drawn from the boxes extend to the minimum and the maximum. Expression of LMO4 mRNA was normalized to that of I8S rRNA.

To investigate the involvement of LMO4 in the PanINIDC pathway, we isolated IDC cells from 8 lesions, PanIN2 cells from 3 lesions, PanIN-1B cells from 14 lesions and normal ductal epithelial cells from 13 ducts by LMD (Figure 2) for quantitative analysis of LMO4 by RT-PCR. As shown in Figure 5, IDC cells expressed significantly higher levels of LMO4 than did normal ductal epithelial or PanIN-1B cells ( $p<0.0001$ for both) or PanIN-2 cells ( $p=$ $0.014)$. The mean $L M O 4$ expression level was $2.19(95 \%$ CI, 1.43 - 2.94) in IDC cells, 0.32 (95\% CI, $0.18-0.45)$ in PanIN-2 cells, 0.41 (95\% CI, $0.27-0.54$ ) in PanIN-1B cells and 0.45 (95\% CI, $0.30-0.60)$ in normal ductal epithelial cells. The difference in LMO4 expression between PanIN-2 and normal ductal cells or between PanIN-1B and normal ductal cells was not significant $(p=0.54$ and $p=0.56$, respectively). These data suggested that LMO4 is overexpressed in pancreatic cancer, especially in the inva-

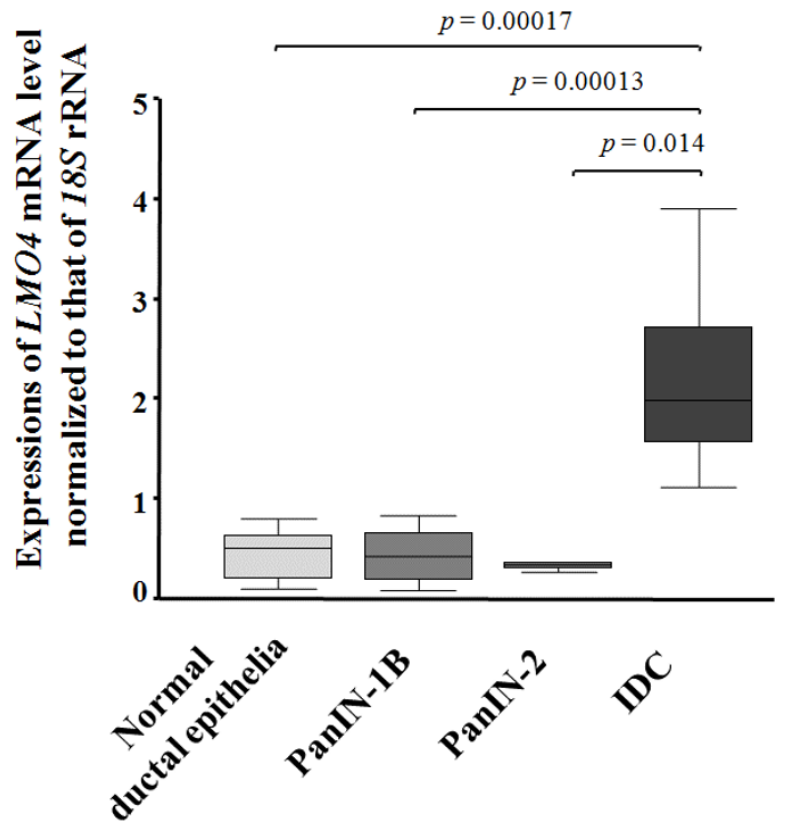

Figure 5

LMO4 expressions in the PanIN-IDC pathway, including I 3 normal ductal epithelial ducts, I 4 PanIN-IB lesions, 3 PanIN-2 lesions, and 8 IDC lesions. IDC cells (mean, 2.19; 95\% Cl, I.43 - 2.94) expressed significantly higher levels of LMO4 than did normal ductal epithelia (mean, $0.45 ; 95 \% \mathrm{Cl}, 0.30-0.60$ ), PanIN-IB (mean, $0.4 \mathrm{I} ; 95 \% \mathrm{Cl}$, $0.27-0.54$ ), or PanIN-2 cells (mean, $0.32 ; 95 \% \mathrm{Cl} 0.18-$ 0.45). The differences in LMO4 expression among PanIN-2, PanIN-IB, and normal ductal epithelial cells are not statistically significant $(p=0.54$ and $p=0.56)$. The bottom and the top edges of the box mark the lower bound and upper bound of the $95 \%$ Confidence Interval for the Mean, respectively. The center horizontal line is drawn at the sample mean. The center vertical lines drawn from the boxes extend to the minimum and the maximum. Expression of LMO4 mRNA was normalized to that of I8S rRNA.

sive step of cancer, but not in the early stage of pancreatic carcinogenesis.

\section{Quantitative analyses of LMO4 expressions in IPMC, IPMB, IPMA and normal ductal cells}

To investigate the correlation of LMO4 expression with the IPMA-IPMC pathway, we microdissected IPMC cells from 5 invasive lesions and 3 non-invasive lesions (CIS), IPMB cells from 15 lesions, IPMA cells from 13 lesions and normal ductal epithelial cells from 6 ducts. We then measured LMO4 expression in these cells by qRT-PCR (Figure 2). As shown in Figure 6, IPMC cells expressed higher levels of LMO4 (mean, 1.79; 95\% CI, $0.99-2.58$ ), than did normal ductal cells $(p<0.001)$, IPMA cells $(p<$ $0.001)$ and IPMB cells $(p=0.003)$. There was no signifi- 


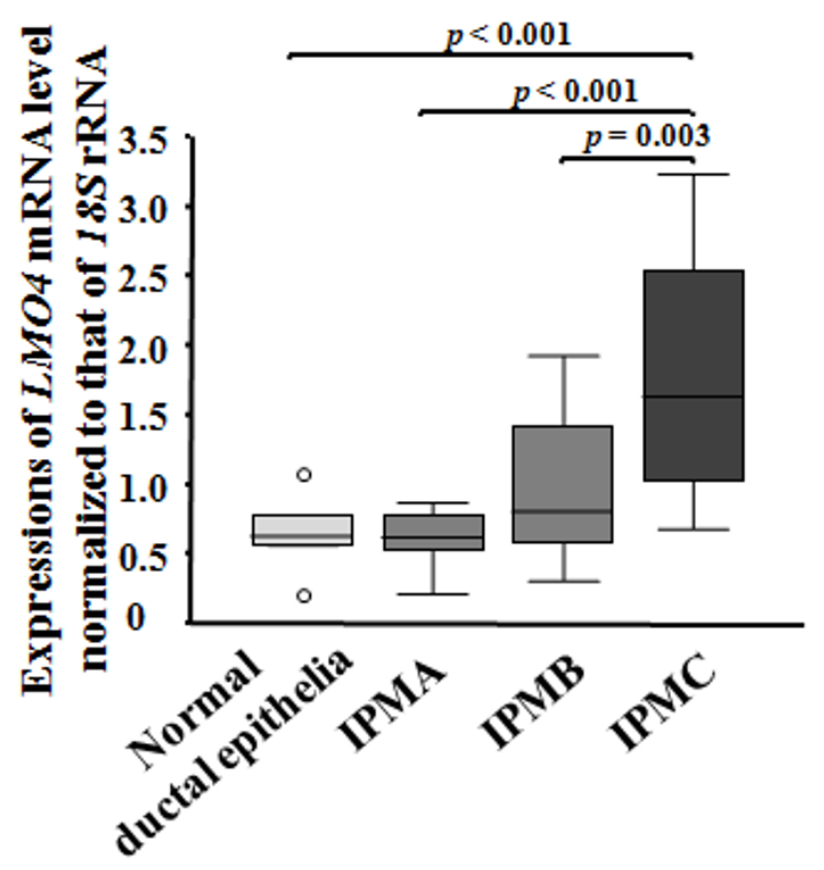

Figure 6

LMO4 expressions in the IPMA-IPMC pathway, including 6 normal ductal epithelial ducts, I 3 IPMA lesions, I 5 IPMB lesions and 8 IPMC lesions (5 for invasive IPMC and 5 for non-invasive IPMCs). IPMC cells expressed significantly higher levels of LMO4 (mean, I.79; $95 \% \mathrm{Cl}, 0.99-2.58$ ) than did IPMB (mean, 0.98; $95 \% \mathrm{Cl}$, $0.69-1.27)(p=0.003)$, IPMA (mean, $0.60 ; 95 \% \mathrm{Cl}, 0.47$ $0.73)(p<0.00 \mathrm{I})$, or normal ductal epithelial cells (mean, $0.65 ; 95 \% \mathrm{Cl}, 0.34-0.95)(p<0.00 \mathrm{I})$. The differences in LMO4 expression between IPMB and IPMA cells $(p=0.09)$, IPMB and normal ductal epithelial cells $(p=0.2)$ and IPMA and normal ductal epithelial cells $(p=0.9)$ are not significant. The bottom and the top edges of the box mark the lower bound and upper bound of the $95 \%$ Confidence Interval for the Mean, respectively. The center horizontal line is drawn at the sample mean. The center vertical lines drawn from the boxes extend to the minimum and the maximum. Expression of LMO4 mRNA was normalized to that of I8S rRNA.

cant difference in $\mathrm{LMO} 4$ expression between invasive IPMC and non-invasive IPMC (CIS). Although the mean LMO4 expression in IPMB cells $(0.98 ; 95 \% \mathrm{CI}, 0.69$ 1.27) was higher than that in IPMA $(0.60 ; 95 \% \mathrm{CI}, 0.47$ 0.73 ) or normal ductal cells $(0.65 ; 95 \% \mathrm{CI}, 0.34-0.95)$, the differences in $\mathrm{LMO} 4$ expression were not significant. Taken together, these data suggested that LMO4 expression may be up-regulated during the late stages of carcinogenesis of IPMN.

\section{Quantitative analyses of LKB I expressions in cultured and microdissected cells, and correlation analyses between LKB I and LMO4 in pancreatic carcinogenesis}

LKB1 (also called STK11) is a tumor suppressor gene in Peutz-Jeghers syndrome [31]. Loss of this gene is found in pancreatic cancer $[32,33]$. Recently, LKB1 was reported to induce p21 expression in collaboration with LMO4 [34]. To investigate the potential role of LMO4 in pancreatic carcinogenesis, we measured LKB1 mRNA expression in cultured and microdissected cells and investigated any correlation between LKB1 and LMO4 expression. In the analysis of cultured cells, we found significant correlation between LKB1 and LMO4 mRNA levels in primary cultured fibroblasts $(\mathrm{n}=6$, spearman test, $p=0.024$; Figure $7 \mathrm{a}$, top). By contrast, there was no significant correlation between LKB1 and LMO4 mRNA levels in cultured cancer cell lines ( $\mathrm{n}=14$, spearman test, $p=0.33$; Figure 7 a bottom). In the analysis of microdissected cells, IDC cells expressed significantly lower levels of LKB1 mRNA than did PanIN-1B or normal ductal cells $(\mathrm{n}=12, p=0.02 ; \mathrm{n}=$ $8 ; p=0.002$, respectively; Figure $7 \mathrm{~b}$ top). There was a significant correlation between LKB1 and LMO4 mRNA levels in non-malignant cells, including normal pancreatic ductal epithelia and PanIN-1B cells $(n=20, p=0.042$, Figure $7 \mathrm{~b}$ middle), but no significant correlation in IDC cells ( $\mathrm{n}=8, p=0.45$, Figure $7 \mathrm{~b}$ bottom).

\section{Discussion}

In the present study, we performed quantitative real-time RT-PCR to measure LMO4 expression during pancreatic carcinogenesis through the PanIN-IDC and IPMA-IPMC pathways. Analyses of cultured cells revealed that 9 of 14 pancreatic cancer cell lines and all primary cultures of pancreatic fibroblasts expressed higher levels of LMO4 than did a non-neoplastic pancreatic ductal cell line. Bulk tissue analysis showed that pancreatic cancer tissues expressed higher levels of LMO4 than non-neoplastic and non-malignant IPMN tissues; however, the difference in LMO4 expression between non-neoplastic tissues and non-malignant IPMN was not significant. To avoid the influence of LMO4-expressing non-ductal cells contained in bulk tissues, we microdissected target cells, such as IDCs, PanINs, IPMNs and non-neoplastic ductal cells, and measured LMO4 expression in the microdissected cells. It is usually difficult to obtain frozen sections of intermediate or high-grade PanIN-2 or PanIN-3 (CIS) or non-invasive IPMC (CIS) lesions. In the present study, we obtained frozen sections from 3 cases of PanIN-2 lesions and 3 of non-invasive IPMC. We found that the LMO4 expression in IDC cells was significantly higher than those in PanIN1B, PanIN-2, and normal ductal cells; however, the PanIN-2 sample number was small. We also found that both invasive and non-invasive IPMC cells expressed 
a

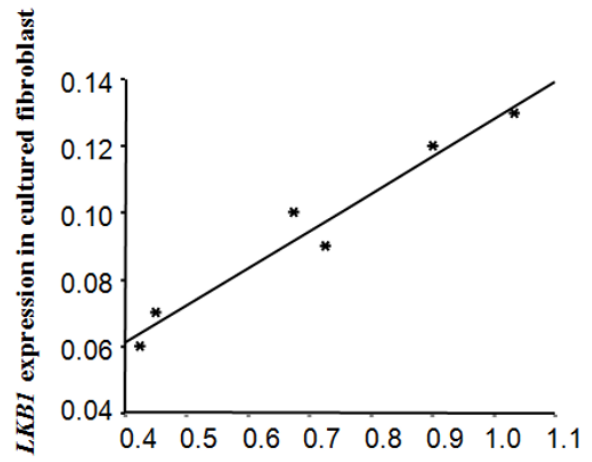

LMO4 expression in cultured fibroblast

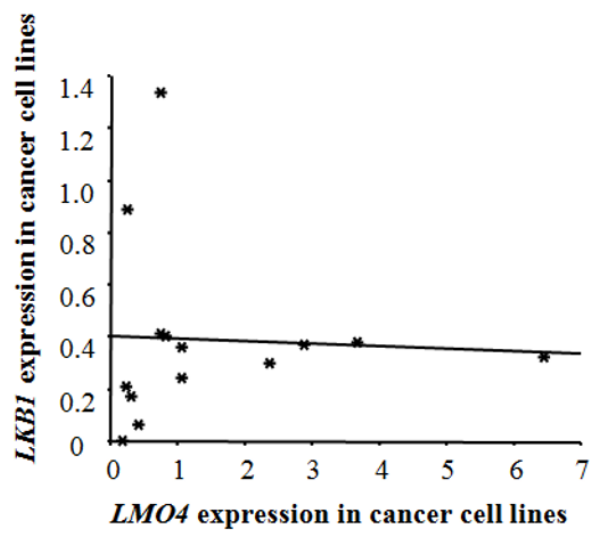

b
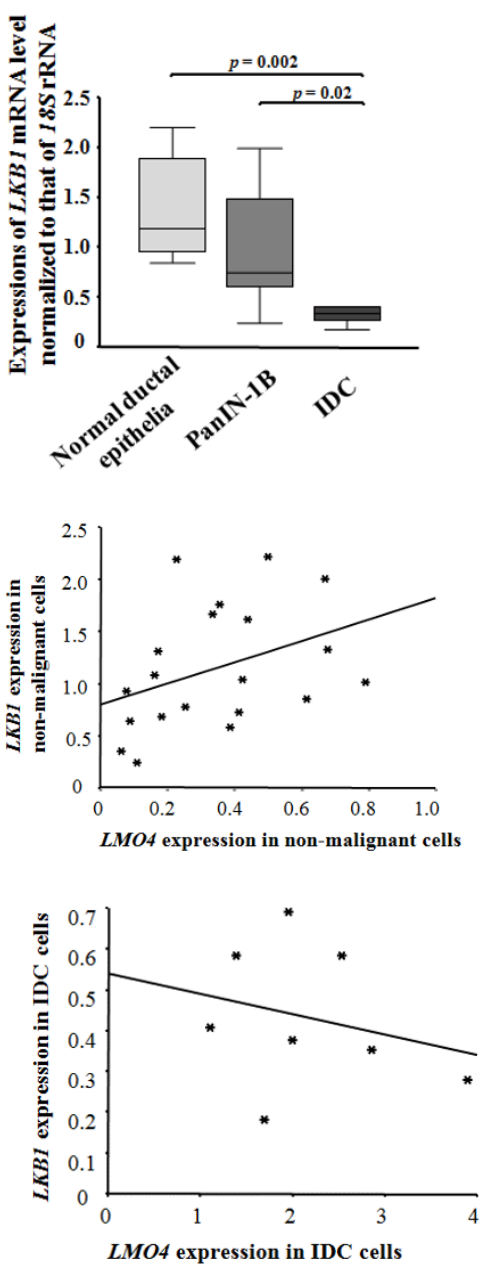

\section{Figure 7}

Correlation analyses between $L K B I$ and $L M O 4$ in pancreatic carcinogenesis. a, Correlation between $L K B I$ and $L M O 4$ in primary cultured fibroblasts (spearman test, $p=0.037$, top) and correlation between $L K B I$ and $L M O 4$ in cultured cancer cell lines (spearman test, $p=0.39$, bottom). b, Expression of $L K B I$ mRNA levels in microdissected normal ducts, PanIN-IB cells, and IDC cells (top). The bottom and the top edges of the box mark the lower bound and upper bound of the $95 \%$ Confidence Interval for the Mean, respectively. The center horizontal line is drawn at the sample mean. The center vertical lines drawn from the boxes extend to the minimum and the maximum. Correlation between $L K B I$ and LMO4 mRNA levels in non-malignant cells (including normal ducts and PanIN-IB cells, spearman test, $p=0.042$, middle), and correlation between $L K B I$ and LMO4 mRNA levels in IDC cells (spearman test, $p=0.453$, bottom). Expression of LMO4 mRNA was normalized to that of $18 \mathrm{~S}$ rRNA.

higher levels of LMO4 than did non-malignant IPMN or normal ductal cells. By contrast, we could not detect any differences in $\mathrm{LMO} 4$ expression among PanIN-1B, PanIN2 and normal ductal cells, or among IPMA, IPMB, and normal ductal cells. Taken together, these data suggested that LMO4 expression is up-regulated in pancreatic cancer but not in low-grade intraductal precursors in both the PanIN-IDC and IPMA-IPMC pathways.

This is the first report to use qRT-PCR for analyses of LMO4 expression during pancreatic carcinogenesis. LMO4 is reported to have an oncogenic role in carcinogenesis and in carcinoma progression in breast cancer and SCC [18-21]. However, the human LMO4 gene is located on chromosome 1 p22.3 [35], which is a region deleted in several human cancers, such as those of liver, skin, and lung [36,37], and Setogawa et al reported that the tumor suppressor LKB1 induces p21 expression in collaboration with LMO4, suggesting that LMO4 may have a tumor suppressor function [34]. In the present study, we found that there was significant correlation between LMO4 and LKB1 in both primary cultured fibroblasts and microdissected 
non-malignant cells, but there was not a significant correlation between LMO4 and LKB1 in cancer cells. We also found the downregulation of LKB1 mRNA in IDC cells, consistent with LKB1's tumor suppressive function. Our data suggest that alteration of the LKB1-LMO4 balance is involved in pancreatic carcinogenesis, although the exact function of $\mathrm{LMO} 4$ in pancreatic carcinogenesis remains unknown. Taken together, there appears to be a conflicting function of $\mathrm{LMO} 4$ in carcinogenesis as a tumor suppressor or as an oncogene; it is reasonable that LMO4, a transcription regulator, may have multiple functions in individual cancers, like E2F1, an another transcription factor, that was reported both as an oncogene by stimulating cell proliferation [38] and as a tumor suppressor by signaling p53-dependent apoptosis [39].

Recently, Murphy et al [40] used immunohistochemical staining and reported that a subset of patients with low LMO4 expression-pancreatic cancers had poor outcomes. In the present study, LMO4 mRNA was not overexpressed in any of the 14 pancreatic cancer cell lines. However, all IDC cells microdissected from cancer tissues showed relatively high expression of LMO4 mRNA although the sample number was small. This might have been the result of using of frozen sections with a histological diagnosis of moderately or well-differentiated adenocarcinoma, which can be microdissected easily. Patients with well-differentiated adenocarcinoma usually have better prognosis [41]; thus the present data may be partially consistent with Murphy's result demonstrating that high LMO4-pancreatic cancers are associated with a significant survival advantage for patients with surgical resection.

Taken together, it remains unclear if $\mathrm{LMO} 4$ has an oncogenic function or a tumor suppressive function in pancreatic carcinogenesis. To better clarify the functional roles of LMO4 in pancreatic carcinogenesis, further examinations such as inhibition experiments using RNAi technology are needed.

In conclusion, the present results showed that LMO4 is overexpressed in pancreatic cancer related to both the PanIN-conventional IDC pathway and the IPMA-IPMC pathway, but not at the early stages of pancreatic carcinogenesis.

\section{Competing interests}

The authors declare that they have no competing interests.

\section{Authors' contributions}

JY participated in the design of the study, carried out the RNA expression analysis, Laser Capture Microdissection studies, statistical analysis, and drafted the manuscript. $\mathrm{KO}$ and KM participated in the design and coordination of the study, performed the statistical analysis, and critically revised the manuscript. LC performed realtime expression analysis and critically revised the manuscript. KN and $\mathrm{HY}$ participated in histologic examination and critically revise the manuscript. HF, TE and HK performed the statistical analysis and critically revised the manuscript. MT planned and coordinated the study, and critically revised the manuscript. All authors have read and approved the final version of the manuscript.

\section{Acknowledgements}

We thank Miyuki Ohmori for expert technical assistance in preparing frozen sections for microdissection, and thank Shoko Sadatomi, Midori Sato, and Emiko Manabe for help in maintaining the cultures of cell lines and clinical samples. This work has been supported by the grants from the Ministry of Education, Culture, Sports, Science and Technology of Japan; the Fukuoka Cancer Society, Pancreas Research Foundation of Japan; Clinical Research Foundation; and Kaibara Morikazu Medical Science Promotion Foundation. We appreciate for the technical supports from the Research Support Center, Graduate School of Medical Sciences, Kyushu University, Japan.

\section{References}

I. Warshaw AL, Fernandez-del Castillo C: Pancreatic carcinoma. N Engl I Med 1992, 326:455-65.

2. Yamamoto M, Ohashi O, Saitoh Y: Japan Pancreatic Cancer Registry: current status. Pancreas 1998, 16:238-42.

3. Matsuno S, Egawa S, Fukuyama S, Motoi F, Sunamura M, Isaji S, et al.: Pancreatic Cancer Registry in Japan: 20 years of experience. Pancreas 2004, 28:219-30.

4. Tanaka M: Important clues to the diagnosis of pancreatic cancer. Roczniki Akademii Medycznej w Bialymstoku (1995) 2005, 50:69-72.

5. House MG, Guo M, lacobuzio-Donahue C, Herman JG: Molecular progression of promoter methylation in intraductal papillary mucinous neoplasms (IPMN) of the pancreas. Carcinogenesis 2003, 24:193-8.

6. Hruban RH, Takaori K, Klimstra DS, Adsay NV, Albores-Saavedra J, Biankin AV, et al.: An illustrated consensus on the classification of pancreatic intraepithelial neoplasia and intraductal papillary mucinous neoplasms. Am J Surg Pathol 2004, 28:977-87.

7. Klimstra DS, Longnecker DS: K-ras mutations in pancreatic ductal proliferative lesions. The American journal of pathology 1994, 145: I547-50.

8. Nakata B, Yashiro M, Nishioka N, Aya M, Yamada S, Takenaka C, et al.: Genetic alterations in adenoma-carcinoma sequencing of intraductal papillary-mucinous neoplasm of the pancreas. Int I Oncol 2002, 21:1067-72.

9. Adsay NV, Conlon KC, Zee SY, Brennan MF, Klimstra DS: Intraductal papillary-mucinous neoplasms of the pancreas: an analysis of in situ and invasive carcinomas in 28 patients. Cancer 2002, 94:62-77.

10. Hruban RH, Adsay NV, Albores-Saavedra J, Compton C, Garrett ES, Goodman SN, et al.: Pancreatic intraepithelial neoplasia: a new nomenclature and classification system for pancreatic duct lesions. Am J Surg Pathol 200I, 25:579-86.

II. Takaori K, Kobashi Y, Matsusue S, Matsui K, Yamamoto T: Clinicopathological features of pancreatic intraepithelial neoplasias and their relationship to intraductal papillary-mucinous tumors. J Hepatobiliary Pancreat Surg 2003, 10:125-36.

12. Longnecker DS, Adsay NV, Fernandez-del Castillo C, Hruban RH, Kasugai T, Klimstra DS, et al.: Histopathological diagnosis of pancreatic intraepithelial neoplasia and intraductal papillarymucinous neoplasms: interobserver agreement. Pancreas 2005, 31 : 344-9.

13. Kenny DA, Jurata LW, Saga Y, Gill GN: Identification and characterization of LMO4, an LMO gene with a novel pattern of expression during embryogenesis. Proc Natl Acad Sci USA 1998, 95: I I257-62.

14. Boehm T, Foroni L, Kaneko Y, Perutz MF, Rabbitts TH: The rhombotin family of cysteine-rich LIM-domain oncogenes: distinct 
members are involved in T-cell translocations to human chromosomes IIpI5 and I IpI3. Proc Natl Acad Sci USA I99I, 88:4367-7I.

15. Royer-Pokora B, Loos U, Ludwig WD: TTG-2, a new gene encoding a cysteine-rich protein with the LIM motif, is overexpressed in acute $T$-cell leukaemia with the $t(I I ; \mid 4)(p \mid 3 ; q I I)$. Oncogene 199|, 6: |887-93.

16. Lu Z, Lam KS, Wang N, Xu X, Cortes M, Andersen B: LMO4 can interact with Smad proteins and modulate transforming growth factor-beta signaling in epithelial cells. Oncogene 2006, 25:2920-30.

17. Racevskis J, Dill A, Sparano JA, Ruan H: Molecular cloning of LMO4I, a new human LIM domain gene. Biochim Biophys Acta 1999, I 445: | 48-53.

18. Visvader JE, Venter D, Hahm K, Santamaria M, Sum EY, O'Reilly L, et al: The LIM domain gene LMO4 inhibits differentiation of mammary epithelial cells in vitro and is overexpressed in breast cancer. Proc Natl Acad Sci USA 200I, 98: | 4452-7.

19. Sum EY, Peng B, Yu X, Chen J, Byrne J, Lindeman GJ, et al.: The LIM domain protein LMO4 interacts with the cofactor CtIP and the tumor suppressor BRCAI and inhibits BRCAI activity. J Biol Chem 2002, 277:7849-56.

20. Sum EY, Segara D, Duscio B, Bath ML, Field AS, Sutherland RL, et al.: Overexpression of LMO4 induces mammary hyperplasia, promotes cell invasion, and is a predictor of poor outcome in breast cancer. Proc Natl Acad Sci USA 2005, 102:7659-64.

21. Mizunuma H, Miyazawa J, Sanada K, Imai K: The LIM-only protein, LMO4, and the LIM domain-binding protein, LDBI, expression in squamous cell carcinomas of the oral cavity. British journal of cancer 2003, 88: $1543-8$.

22. Wang N, Lin KK, Lu Z, Lam KS, Newton R, Xu X, et al.: The LIMonly factor LMO4 regulates expression of the BMP7 gene through an HDAC2-dependent mechanism, and controls cell proliferation and apoptosis of mammary epithelial cells. Oncogene 2007, 26:643I-4I.

23. Kitamura N, Murata S, Abe H, Hanasawa K, Tsukashita S, Tani T: Obstructive jaundice in a metastatic tumor of the pancreas from breast cancer: a case report. Japanese Journal of clinical oncology 2003, 33:93-97.

24. Schutte M, Hruban RH, Hedrick L, Cho KR, Nadasdy GM, Weinstein $\mathrm{CL}$, et al.: DPC4 gene in various tumor types. Cancer research 1996, 56:2527-30.

25. Ohuchida K, Mizumoto K, Murakami M, Qian LW, Sato N, Nagai E, et al.: Radiation to stromal fibroblasts increases invasiveness of pancreatic cancer cells through tumor-stromal interactions. Cancer research 2004, 64:3215-22.

26. Yu J, Ohuchida K, Mizumoto $K$, Ishikawa N, Ogura $Y$, Yamada $D$, et al.: Overexpression of c-met in the early stage of pancreatic carcinogenesis; altered expression is not sufficient for progression from chronic pancreatitis to pancreatic cancer. World J Gastroenterol 2006, I 2:3878-82.

27. Chomczynski P, Sacchi N: Single-step method of RNA isolation by acid guanidinium thiocyanate-phenol-chloroform extraction. Analytical biochemistry 1987, 162:156-9.

28. Tachikawa T, Irie T: A new molecular biology approach in morphology: basic method and application of laser microdissection. Med Electron Microsc 2004, 37:82-8.

29. Liu N, Furukawa T, Kobari M, Tsao MS: Comparative phenotypic studies of duct epithelial cell lines derived from normal human pancreas and pancreatic carcinoma. The American journal of pathology 1998, 153:263-9.

30. Ouyang H, Mou L, Luk C, Liu N, Karaskova J, Squire J, et al.: Immortal human pancreatic duct epithelial cell lines with near normal genotype and phenotype. The American journal of pathology 2000, I57:|623-31.

31. Jenne DE, Reimann H, Nezu J, Friedel W, Loff S, Jeschke R, et al:: Peutz-Jeghers syndrome is caused by mutations in a novel serine threonine kinase. Nature genetics 1998, 18:38-43.

32. Sato N, Rosty C, Jansen M, Fukushima N, Ueki T, Yeo CJ, et al:: STKI I/LKB I Peutz-Jeghers gene inactivation in intraductal papillary-mucinous neoplasms of the pancreas. The American journal of pathology 200I, I 59:20I7-22.

33. Su GH, Hruban RH, Bansal RK, Bova GS, Tang DJ, Shekher MC, et al.: Germline and somatic mutations of the STK I I/LKB I PeutzJeghers gene in pancreatic and biliary cancers. The American journal of pathology 1999, I54:1835-40.
34. Setogawa T, Shinozaki-Yabana S, Masuda T, Matsuura K, Akiyama T: The tumor suppressor LKBI induces $\mathrm{P} 2 \mathrm{I}$ expression in collaboration with LMO4, GATA-6, and Ldb I. Biochemical and biophysical research communications 2006, 343: I 186-90.

35. Tse E, Grutz G, Garner AA, Ramsey Y, Carter NP, Copeland N, et al:: Characterization of the Lmo4 gene encoding a LIM-only protein: genomic organization and comparative chromosomal mapping. Mamm Genome 1999, 10:1089-94.

36. Emi M, Matsumoto S, lida A, Tsukamoto K, Nakata T, Yokota T, et al:: Correlation of Allelic Losses and Clinicopathological Factors in Primary Breast Cancers. Breast Cancer 1997, 4:243-6.

37. Hoggard N, Brintnell B, Howell A, Weissenbach J, Varley J: Allelic imbalance on chromosome I in human breast cancer. II. Microsatellite repeat analysis. Genes, chromosomes \& cancer 1995, I 2:24-31.

38. Singh $\mathrm{P}$, Wong $\mathrm{SH}$, Hong $\mathrm{W}$ : Overexpression of E2F-I in rat embryo fibroblasts leads to neoplastic transformation. The EMBO journal 1994, 13:3329-38.

39. Jamshidi-Parsian A, Dong Y, Zheng X, Zhou HS, Zacharias W, McMasters KM: Gene expression profiling of E2F-I-induced apoptosis. Gene 2005, 344:67-77.

40. Murphy NC, Scarlett CJ, Kench JG, Sum EYM, Segara D, Colvin EK, et al.: Expression of LMO4 and outcome in pancreatic ductal adenocarcinoma. British Journal of Cancer 2008, 98:537-4I.

41. Pongprasobchai S, Pannala R, Smyrk TC, Bamlet W, Pitchumoni S, Ougolkov A, et al:: Long-term survival and prognostic indicators in small $(<$ or $=2 \mathrm{~cm})$ pancreatic cancer. Pancreatology 2008, 8:587-92.

Publish with Bio Med Central and every scientist can read your work free of charge

"BioMed Central will be the most significant development for disseminating the results of biomedical research in our lifetime. "

Sir Paul Nurse, Cancer Research UK

Your research papers will be:

- available free of charge to the entire biomedical community

- peer reviewed and published immediately upon acceptance

- cited in PubMed and archived on PubMed Central

- yours - you keep the copyright

Submit your manuscript here:

http://www.biomedcentral.com/info/publishing_adv.asp

BioMedcentral 